Article

\title{
Improving the Tribological Properties of Gear Synchronizations by Adjusting the Metalworking Fluid Composition of the Grinding Process
}

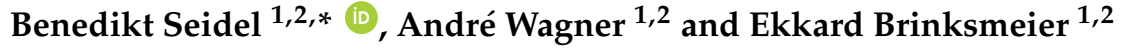 \\ 1 Foundation Institute of Materials Science, Badgasteiner Straße 3, 28359 Bremen, Germany; \\ wagner@iwt-bremen.de (A.W.); brinksmeier@iwt.uni-bremen.de (E.B.) \\ 2 University of Bremen and MAPEX Center for Materials and Processes, Bibliothekstr. 1, \\ 28359 Bremen, Germany \\ * Correspondence: seidel@iwt-bremen.de; Tel.: +49-(0)421-218-51182
}

Received: 19 June 2017; Accepted: 18 July 2017; Published: 20 July 2017

\begin{abstract}
The modification of tribological properties of highly loaded components by selecting a suitable manufacturing process is state-of-the-art. Beyond the generation of microgeometrical structures, the present study investigates the potential of chemical alterations, i.e., metalworking fluid additives engaged in a grinding process to improve the chemical surface properties of machined gear synchronizations. These gearbox components ensure a uniform switching operation by harmonizing the number of revolutions between the power transmitting components by friction. A short running-in phase and a friction coefficient which is constant over the entire duration of use are required. The results show that the addition of polysulfide as well as zincdialkyldithiophosphate in the metalworking fluid could considerably reduce the friction coefficient fluctuations and the running-in phase of the generated synchronizations in later operation tests. The wear distances were lower although the machined parts revealed higher surface roughnesses as the reference workpieces, which indicates the formation of sorption or reaction layers of the additives with the metal surface.
\end{abstract}

Keywords: tribology; metalworking fluid; grinding; gear synchronization

\section{Introduction}

Metalworking processes such as milling, turning, grinding or lapping are usually conducted to meet defined shape, size and surface tolerances of the workpiece. The selection of metalworking fluids, tools and process parameters is set with respect to a productive and stable process. With regard to increasing requirements on components and in particular to their surface layer properties, the potential of metalworking processes to influence the components surface layer in a desired way became the subject of industrial developments [1]. Especially the improvement of characteristics such as residual stresses, hardness and tribological properties is of interest. Tribological experiments with unidirectional ground steel samples indicated that the friction coefficient as well as the resulting wear volume depend on the orientation of the grinding marks [2]. The influence of the surface topography resulting from different metalworking processes on the running-in phase and the wear rate of tribological systems was investigated by Geoke et al. The authors described that the wear rate and the duration of the running-in phase of friction pairings were influenced stronger by the surface structure resulting from the manufacturing process than by the surface finish [3]. Karpuschewski et al. showed that friction and wear of cylinder running surfaces in combustion engines can be reduced by adapted honing processes [4]. By adjusting the dressing conditions in a grinding process, the running-in phase of gear synchronizations could be modified. The lower the overlapping rate in dressing $U_{d}$ was set, the higher 
was the resulting surface roughness of the machined synchronous cones, which led to more constant friction coefficients and shorter running-in phases of the synchronizations in later operation tests [5].

Chemical interactions between the metalworking fluid and the workpiece surface can influence the chemical composition of the new surface layer and, therefore, besides the workpiece topography, influence the tribological properties of the machined sample as well. Walter could detect sulfurous sorption and reaction layers on the workpiece surface occurring from sulfur additives in the metalworking fluid [6]. Steel samples, which were ground with various metalworking fluid compositions, showed different friction behavior and wear rates in tribological pin-on-disk tests [7].

To meet the technical requirements, not all tribological stressed components need a friction coefficient, which is as low as possible. In the case of certain friction parings like gearbox synchronizations, a stable friction coefficient level is required during the entire working life in order to guarantee fluent switching operations. The manual gearbox is one of the most established models in the European vehicle market. Gear synchronizations ensure a uniform switching operation by harmonizing the number of revolutions between the power-transmitting components initially by friction and subsequently by form lock. Synchronizations usually are designed as cone friction clutches. They consist of a clutch body (synchronizer cone) which is connected to a gear, a synchronizer ring with inserted notches for oil removal, a synchronizer hub which is connected with the main shaft and a sliding sleeve, guided by the synchronizer hub via an internal gearing. After the switching process, the synchronizer hub and the gear have identical number of revolutions [8]. During the synchronization, the different speed between the shaft and the gear is reduced by friction between the synchronizer ring and the synchronizer cone. For shifting to a higher gear, the motor-sided gear elements must be decelerated and accelerated to change to a lower gear. A high and constant friction coefficient between the involved tribological partners is essential for a reliable function [9].

The running-in phase is of high importance for the function and life time of synchronizations. Particularly in the running-in phase, the coefficient of friction may fluctuate, which can have a negative influence on the operating behavior, as well as on the service life duration of the synchronization [10]. Therefore, short running-in phases with low friction value fluctuations are required. Typically the running-in phase begins with high wear rates, which compensates macroscopic shape and position deviations. With each gear shift, the contact conditions change slightly, whereby the two friction partners have to adapt to each other again [11].

The presented work investigates how the tribological behavior of gear synchronizations can be influenced positively by adjusting the metalworking fluid composition in the machining process. Of central interest is a reduction of friction coefficient fluctuations and the duration of the running-in phase. Therefore, in the external cylindrical plunge grinding process, which is engaged for the final machining step in the process chain of synchronizer cones, the composition of the applied metalworking fluid is varied in several defined steps. The subsequent evaluation is conducted on a synchronization test facility. It executes defined gear shifts and monitors relevant parameters, especially the coefficient of friction and the wear between synchronizer cone and ring in axial direction.

\section{Experimental Set-Up}

The machining of the synchronizer cones was performed on an external ground grinding machine (Bahmüller type B44-2 CNC) with a Siemens control type 840D. A conventional vitrified grinding wheel 89A120K11V3 (Ø400 mm) from Tyrolit was chosen as the tool. The process forces in tangential and normal directions were monitored with a piezoelectric dynamometer from Kistler (type 9167). The parameters for the external cylindrical plunge grinding process (fine grinding) are summarized in Table 1. 
Table 1. Parameters external cylindrical plunge grinding process (fine grinding).

\begin{tabular}{cc}
\hline Parameter & Value \\
\hline External Cylindrical Plunge Grinding \\
\hline Grinding wheel circumferential speed $\mathrm{v}_{\mathrm{c}}$ & $35 \mathrm{~m} / \mathrm{s}$ \\
Workpiece circumferential speed $\mathrm{v}_{\mathrm{w}}$ & $17.5 \mathrm{~m} / \mathrm{min}$ \\
Depth of cut $\mathrm{a}_{\mathrm{e}}$ & $0.03 \mathrm{~mm}$ \\
Feed per revolution $\mathrm{f}$ & $0.001 \mathrm{~mm} / \mathrm{U}$ \\
Specific material removal rate $\mathrm{Q}^{\prime}{ }_{\mathrm{w}}$ & $0.29 \mathrm{~mm}^{2} / \mathrm{s}$ \\
\hline Dressing with Single-Point Dresser \\
\hline Overlapping rate in dressing $\mathrm{U}_{\mathrm{d}}$ & 8 \\
Depth of dressing cut $\mathrm{a}_{\mathrm{ed}}$ & $0.02 \mu \mathrm{m}$ \\
\hline
\end{tabular}

Polyalphaolefine (PAO) from one production batch was applied as base oil for the non-water miscible metalworking fluid. PAO is a synthetic hydrocarbon which reveals, compared to e.g., mineral oil, a high defined chemical structure. The investigated additives are polysulfide (PS) and zincdialkyldithiophosphate (ZnDTP). Five different metalworking fluid compositions, summarized in Table 2, were applied in the experiments.

Table 2. Metalworking fluid (MWF) compositions of polyalphaolefine (PAO), polysulfide (PS) and zincdialkyldithiophosphate (ZnDTP).

\begin{tabular}{cccccc}
\hline No. & $\mathbf{1}$ & $\mathbf{2}$ & $\mathbf{3}$ & $\mathbf{4}$ & $\mathbf{5}$ \\
\hline PAO (\%) & 100 & 95 & 90 & 95 & 90 \\
PS (\%) & - & 5 & 10 & - & - \\
ZnDTP $(\%)$ & - & - & - & 5 & 10 \\
\hline
\end{tabular}

In industrial practice, PS is a common so-called "extreme-pressure" (EP) additive in metalworking fluids. A PS molecule is constituted of three to five sulfur atoms between two hydrocarbon chains. Under pressure it forms protective layers on the tribologically loaded surfaces, thereby reducing friction and wear. As more sulfur is bound in the molecule, the higher is its activity and, respectively, the probability of chemisorption with oxidic groups of the metal surface [12].

ZnDTP is an established additive for lubricants in tribological systems such as gear boxes. The complex molecule contains phosphor, zinc and sulfur atoms. According to its wear reducing properties, it is often classified as "anti-wear" (AW) additive. A further positive characteristic is the inhibition of oxidation processes of metal surfaces as well as oil components. The wear protection of ZnDTP is explained with the formation of so-called phosphate glass layers on metal surfaces. The formation can be induced by thermal load as well as by thermo-mechanical load as it occurs in tribological systems. The generation by thermo-mechanical load enables the formation of harder layers by implementing iron ions. However, the exact mechanisms of the layer generation are unknown. The structure of phosphate glass layers with implemented iron ions is schematically illustrated in Figure 1. It is inhomogeneous and several components such as zinc and iron ions show concentration gradients. A complete phosphate glass layer can avoid direct contact of the friction partners [13,14].

The supply in the process was performed by a flat jet nozzle and a flow rate of $Q_{M W F}=25 \mathrm{~L} / \mathrm{min}$. The workpieces (Figure 2) are cones made of the material $1.7139 / 16 \mathrm{MnCrS5}$ with a maximum diameter of $d=66 \mathrm{~mm}$ and a width of $b=12 \mathrm{~mm}$. Prior to the grinding the surface layer was hardened. After the grinding process, the workpiece surface revealed a hardness of $58 \pm 2 \mathrm{HRC}$. To identify outliers, each grinding experiment was performed three times. 


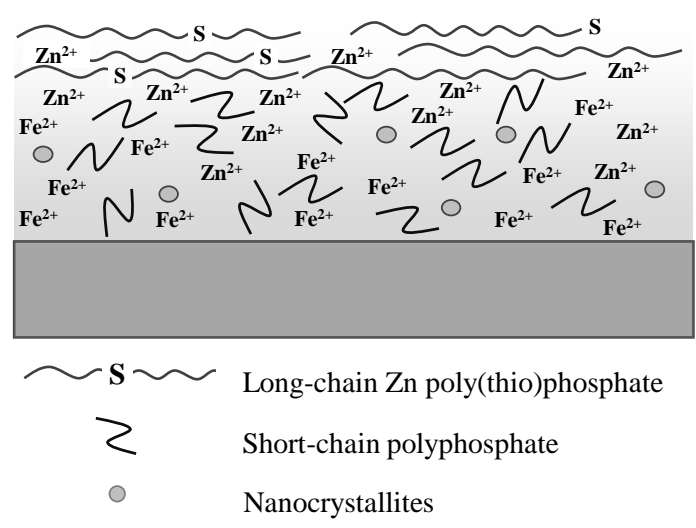

Figure 1. Schematically illustration of a phosphor glass layer generated by tribological load according to [13].

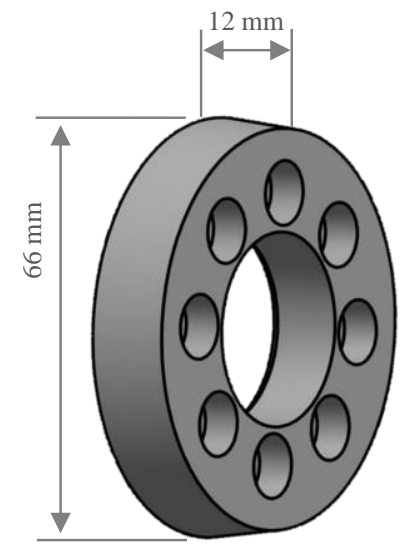

Figure 2. Workpiece synchronizer cone of 1.7139/16MnCrS5.

The experimental investigations of the friction behavior of the machined synchronizations were conducted at a synchronization test facility. The basic principle of the device is a friction surface attached to the test shaft, which accelerates to a predetermined speed and is decelerated subsequently with the investigated counter friction surface [10]. The input variables of the shift tests are summarized in Table 3.

Table 3. Parameters shift tests.

\begin{tabular}{cc}
\hline Parameter & Value \\
\hline Steel synchronizer cone & $1.7139 / 16 \mathrm{MnCrs} 5$ \\
Brass synchronizer ring & $2.0550 / \mathrm{CW} 713 \mathrm{R}$ \\
Circumferential speed before gear shift $\mathrm{v}_{\text {rel }}$ & $3.3 \mathrm{~m} / \mathrm{s}$ \\
Number of revolutions before gear shift $\mathrm{n}$ & $1000 \mathrm{~min}^{-1}$ \\
Axial force $\mathrm{F}_{\mathrm{ax}}$ & $500 \mathrm{~N}$ \\
Total shifts & 7000 \\
Cycle time $\mathrm{t}_{\mathrm{s}}$ & $3 \mathrm{~s}$ \\
Transmission oil & $100 \% \mathrm{PAO}$ \\
Transmission oil temperature $\mathrm{T}_{1}$ & $80{ }^{\circ} \mathrm{C}$ \\
\hline
\end{tabular}

During the experiments, the number of revolutions $\mathrm{n}$ as well as the axial force $\mathrm{F}_{\mathrm{ax}}$ and the torsion moment $\mathrm{M}_{\mathrm{t}}$ were monitored. The friction coefficient $\mu$, the central parameter of the tests, is derived from the torque. At each shift, the friction coefficient has been recorded when $50 \%$ of the speed adjustment were accomplished. Additionally, the position of the shift fork is measured after each gear 
shift in order to determine the wear between the two friction partners in axial direction. The error bars in the charts indicate the $\mathrm{min} / \mathrm{max}$-deviation within the three retries from the mean value. To evaluate the surface characteristics of the synchronizer ring, a surface profiler (type MarSurf XR20) was used. The surface roughness $\mathrm{Rz}$ was measured before and after the shift tests to evaluate the effect of the shifts experiments on the surface topography.

\section{Results and Discussion}

In the following section, the results of the shift tests are presented and discussed. The influence of the applied additives PS and ZnDTP is described separately.

\subsection{Variation of the Polysulfide (PS) Concentration}

The surface roughness Rz of the circumferential surface of the synchronizer cones before and after the shift tests are depicted in Figure 3.

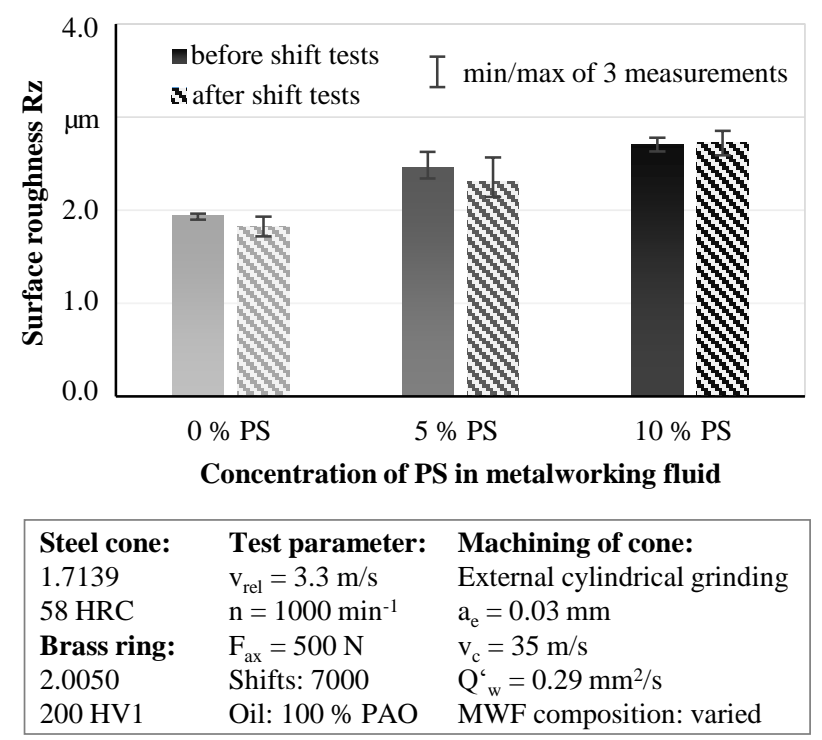

Figure 3. Surface roughness Rz of the synchronizer cones machined with varied proportions of PS in the metalworking fluid before and after the shift tests.

The data indicate a correlation between the concentration of PS in the applied metalworking fluid and the resulting roughness of the machined surface. The higher the ratio of PS was, the higher was the surface roughness Rz. Especially, the rise from $0 \%$ to $5 \%$ PS led to an increase of surface roughness of approximately $30 \%$ from $\mathrm{Rz}=1.9 \mu \mathrm{m}$ to $2.5 \mu \mathrm{m}$. This increase can be correlated to different process forces in the grinding process. Due to the lubricating ability of the PS, the increase of the additive from $0 \%$ to $5 \%$ leads to a rise of the grinding normal force from $F_{n}=10.4 \mathrm{~N}$ to $32.0 \mathrm{~N}$. As a consequence of the higher normal forces, the grinding wheel topography generated deeper traces in the workpiece surface. However, the influence of the following shift test on the surface topography is relatively low. The deviations of the $\mathrm{Rz}$ value before and after the shift tests remain within the statistical variations.

The development of the friction coefficient $\mu$ in the shift tests is shown in Figure 4. For each of the three investigated PS concentrations of $0 \%, 5 \%$ and $10 \%$, the chart shows the progress of one sample. The developments of the friction coefficient among the three retries for each additive concentration are very similar. For a higher comparability, only one representative graph is presented for each metalworking fluid composition. 


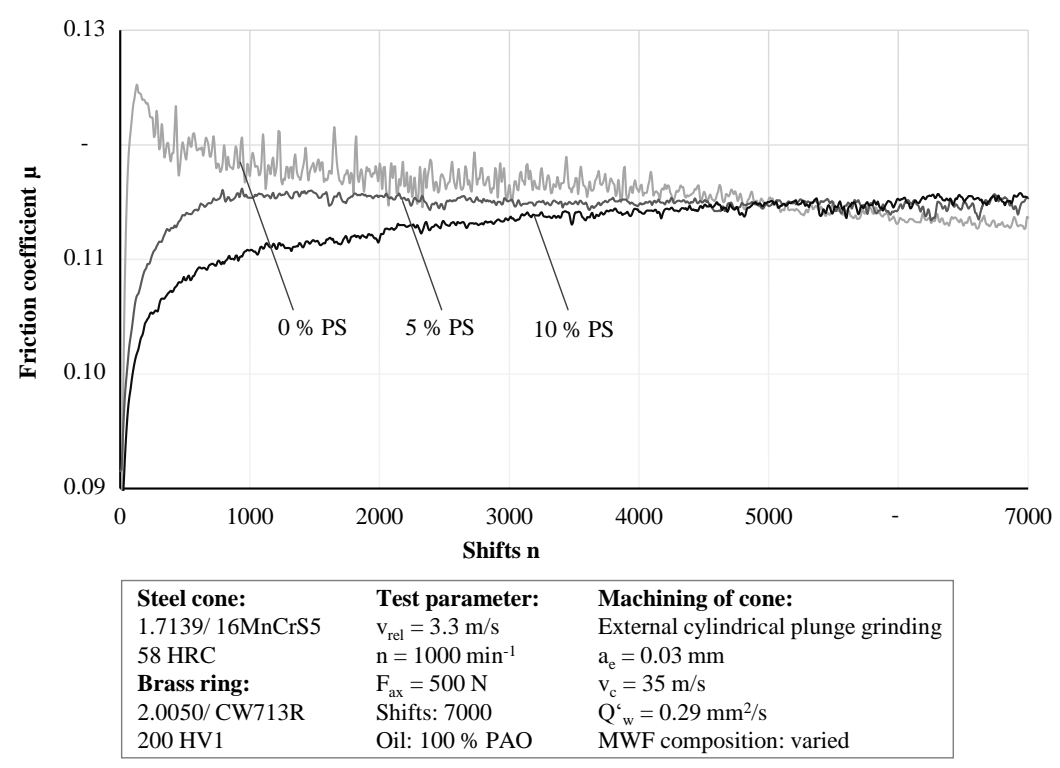

Figure 4. Influence of polysulfide (PS) in the metalworking fluid on the friction coefficient $\mu$ of the synchronization in the shift tests.

The development of the friction coefficient revealed distinct differences depending on the ratio of PS in the applied metalworking fluid. The synchronization machined with $100 \%$ PAO (0\% PS) showed immediately after the beginning of the experiment a rapid increase of the friction coefficient, which ended after around 140 shifts. In the following, the friction coefficient descended continuously for the rest of the shift test. Thereby, especially within the first 4000 shifts, the friction coefficient was highly fluctuating.

The addition of $5 \%$ PS to the applied metalworking fluid changed the tribological behavior of the synchronization in later operation. The friction coefficient increased slower in the beginning and remained subsequently on a relatively constant level. The running-in phase was completed after approximately 1000 shifts and the fluctuations were significantly lower. With $10 \%$ PS concentration, the friction coefficient increased even slower and took more shifts to reach a stable level.

Regarding the performance of the synchronization in operation, the concentration of $5 \%$ PS in the metalworking fluid seemed to be the optimum. The lower PS concentration led to higher fluctuations of the friction coefficient. In contrast, 10\% PS in the metalworking fluid enlarged the running-in phase.

The wear behavior is a further property of tribological systems. For the measurement of the wear, the position of the shift fork has been recorded at each shift. The wear in axial direction $\mathrm{s}$ is the distance that the tribological partners approached to each other in the course of the experiment. Figure 5 shows how the PS in the metalworking fluid influenced the formation of wear between the tribological partners.

The cones ground with PS containing metalworking fluid revealed significantly less wear than the cones machined without PS. The cones machined with 5\% and 10\% PS in the metalworking fluid showed no significant differences in wear distances. The wear distance can be correlated to the friction coefficient development. The high friction coefficient fluctuations of the $0 \%$ PS sample indicate that the tribological partners took more time to adapt to each other and build a tribological system with a constant friction coefficient. The consequence was a higher wear distance in axial direction. A comparison of the wear data with the surface roughness Rz enables the further conclusions that the amount of wear does not correlate positively with the surface roughness Rz. The samples with higher roughness showed lower wear in the shift test. This observation is different to previous experiments Seidel et al. described in [5], where the highest wear distance was caused by the highest surface roughness. Thereby, chemical influences were excluded by applying a constant metalworking fluid composition. 


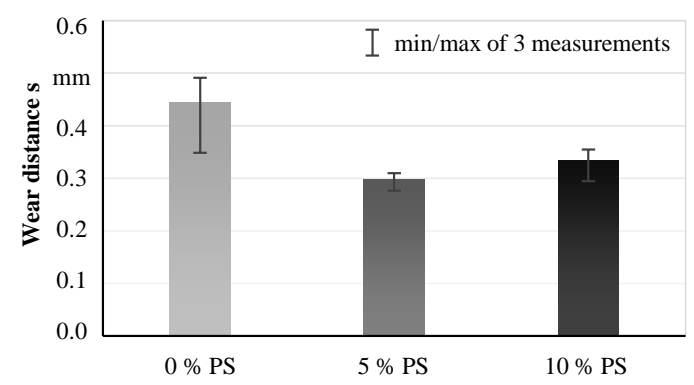

Concentration of PS in metalworking fluid

\begin{tabular}{|lll|}
\hline Steel cone: & Test parameter: & Machining of cone: \\
1.7139 & $\mathrm{v}_{\text {rel }}=3.3 \mathrm{~m} / \mathrm{s}$ & External cylindrical grinding \\
$58 \mathrm{HRC}$ & $\mathrm{n}=1000 \mathrm{~min}^{-1}$ & $\mathrm{a}_{\mathrm{e}}=0.03 \mathrm{~mm}$ \\
Brass ring: & $\mathrm{F}_{\mathrm{ax}}=500 \mathrm{~N}$ & $\mathrm{v}_{\mathrm{c}}=35 \mathrm{~m} / \mathrm{s}$ \\
2.0050 & Shifts: 7000 & $\mathrm{Q}_{\mathrm{w}}=0.29 \mathrm{~mm}^{2} / \mathrm{s}$ \\
$200 \mathrm{HV} 1$ & Oil: $100 \%$ PAO & $\mathrm{MWF}$ composition: varied \\
\hline
\end{tabular}

Figure 5. Wear distance $s$ in axial direction in the shift tests of the synchronizations machined with varied proportions of PS in the metalworking fluid.

From the evaluation of friction and wear of the tribological systems, it can be concluded that the PS in the metalworking fluid influenced the tribological behavior of the synchronization. The formation of sorption and reaction layers of PS on the metal surface as they were described by Walter et al. [6] could therefore be a possible explanation. These layers could support the formation of a boundary layer with a constant friction behavior and reduce the wear distance. Although the cones revealed a surface with higher roughness, they caused less wear in the shift tests. Pressure, temperature and contact time in the grinding process obviously have been sufficient, to enable the generation of PS layers on the metal surfaces which are stable enough to influence the tribological properties of the synchronization in later operation.

That the cone surfaces are hardly influenced during the 7000 shifts leads to the further conclusion that the wear happened completely on the synchronizer rings. These differences are reasonable due to the distinct hardness differences of 58 HRC (synchronizer cones) compared to approximately $10 \mathrm{HRC}$ (200 HV1) (synchronizer rings). In tribological systems, the harder friction partners reveal less wear as the softer friction partners. This relation between the hardness and the wear resistance in materials has been described in various works [15,16]. Ehtemam-Haghighi et al. showed that the wear of the investigated material is related to its ability to resist elastic strain to failure, which is described by the ratio $\mathrm{H} / \mathrm{E}$ (hardness $\mathrm{H}$ to elastic modulus $\mathrm{E}$ ). A higher $\mathrm{H} / \mathrm{E}$ ratio indicated a higher wear resistance of the material [16].

\subsection{Variation of the Zincdialkyldithiophosphate (ZnDTP) Concentration}

The surface roughness $\mathrm{Rz}$ of the cones machined with varied proportions of $\mathrm{ZnDTP}$ in the metalworking fluid are shown in Figure 6. Comparing to the experiments with PS, the ZnDTP led to an increase of the surface roughness resulting from the grinding process. Between the ZnDTP-concentration of $0 \%$ and 5\%, the Rz-values increased from approximately $\mathrm{Rz}=1.9 \mu \mathrm{m}$ to $3.0 \mu \mathrm{m}$. The variation of $\mathrm{ZnDTP}$ from $5 \%$ and $10 \%$ led to no significant differences of surface roughness.

In contrast to the test series with PS, the increasing roughness can only be explained partly with the grinding forces in the machining process. Between $0 \%$ and $5 \%$ concentration of $\mathrm{ZnDTP}$, the grinding normal force increased from approximately $F_{n}=10.4 \mathrm{~N}$ to $18.1 \mathrm{~N}$. With further increasing ZnDTP concentration to $10 \%$, the normal force is decreasing back to $F_{n}=12.9 \mathrm{~N}$, while the resulting surface roughness of the cones remained constant. The influences of the ZnDTP on the grinding process and the resulting surface layer properties seem to be complex. It has to be considered that ZnDTP is an additive for gear oils rather than for metalworking fluids. During the shift tests, the surface roughness 
was slightly decreasing for all metalworking fluid compositions. However, the differences remain within the statistical variations.

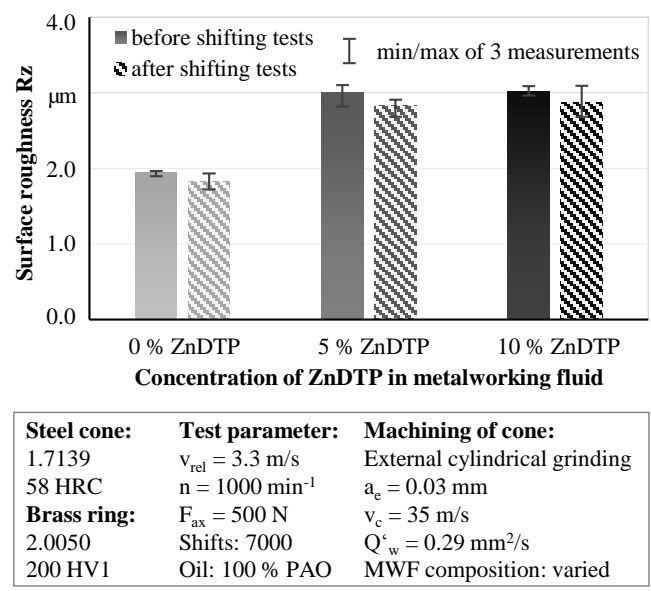

Figure 6. Surface roughness $\mathrm{Rz}$ of the synchronizer cones machined with various proportions of ZnDTP in the metalworking fluid before and after the shift tests.

The development of the friction coefficient $\mu$ in the course of the first 7000 shifts is illustrated in Figure 7. For each metalworking fluid, the data of one representative sample are shown. As can be seen, the influence of the ZnDTP on the friction coefficient depends on the additive concentration. Thereby, the strongest effect reveals the metalworking fluid with $5 \% \mathrm{ZnDTP}$.

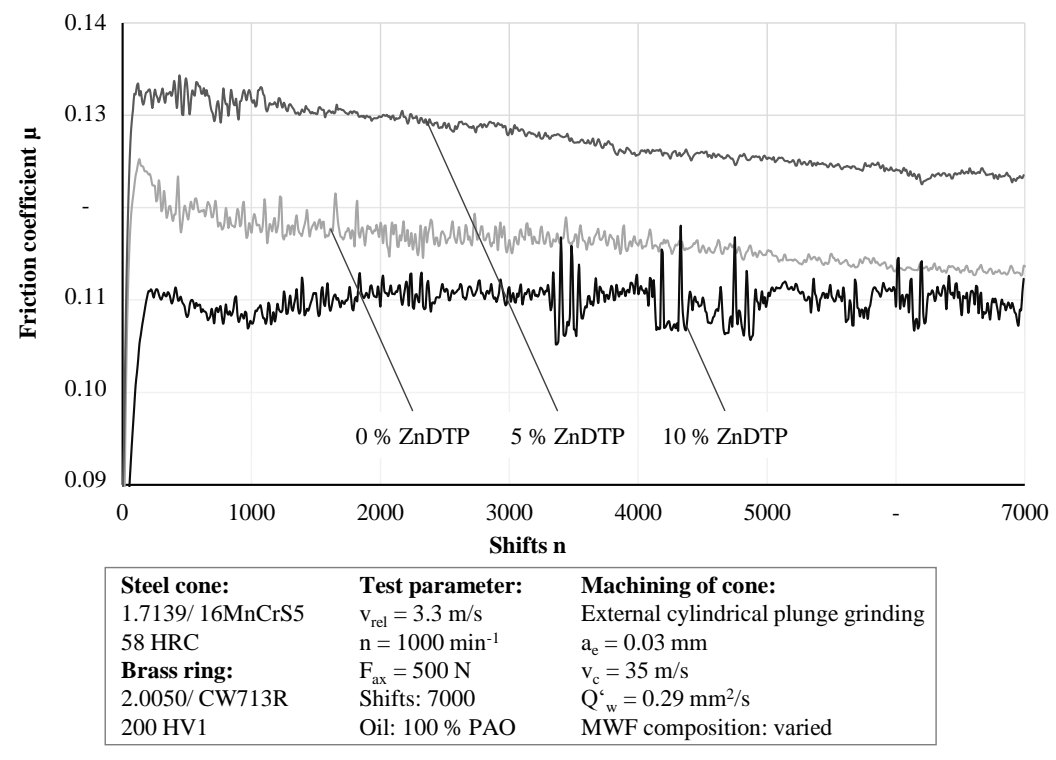

Figure 7. Influence of zincdialkyldithiophosphate (ZnDTP) in the metalworking fluid on the friction coefficient $\mu$ of the synchronization in the shift tests.

The synchronization machined with 100\% PAO (0\% ZnDTP) showed straight after the beginning a rapid increase which ended after approximately 140 shifts. For the rest of the shift test the friction coefficient decreased continuously. Especially within the first 4000 shifts, the friction coefficient showed high fluctuations. The addition of $5 \% \mathrm{ZnDTP}$ to the metalworking fluid reduced the fluctuations of the friction coefficient significantly. After approximately 1300 shifts, the running-in phase was completed. In the following, the friction coefficient showed a homogenous development although it was slightly decreasing over time. 
However, the addition of another 5\% ZnDTP to the applied metalworking fluid (total of $10 \%$ ZnDTP) changed the friction coefficient of the synchronization considerably. It fluctuated even more than the friction coefficient of the synchronization machined with $0 \% \mathrm{ZnDTP}$. A running-in phase is not observable, at least not within the investigated first 7000 shifts. Regarding the friction coefficient, the concentration of $5 \% \mathrm{ZnDTP}$ in the metalworking fluid is an optimum.

The wear in axial direction of the synchronizations during the shift tests correlates to the friction coefficient progress (comp. Figure 8). The metalworking fluid composition with $0 \%$ as well as $10 \%$ ZnDTP led to a very unsteady friction coefficient and caused subsequently a higher wear distance, too. The synchronizations machined with 5\% ZnDTP revealed a smooth and constant friction behavior and led consequently to less wear.

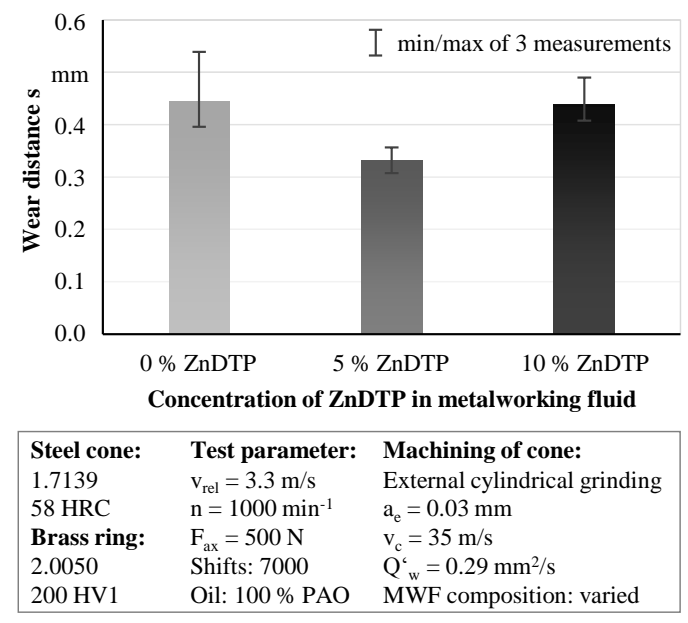

Figure 8. Wear distance in axial direction in the shift tests of the synchronizations machined with varied proportions of $\mathrm{ZnDTP}$ in the metalworking fluid.

The wear distance and the surface roughness data showed no positive correlation. Although the surface roughness Rz remained constant between 5\% and 10\% ZnDTP in the metalworking fluid, the wear distance increased in the shift tests about $33 \%$.

It can be gathered that there is a significant influence of the investigated ZnDTP on the tribological behavior of the generated synchronizations. The formation of phosphor glass layers in the grinding process with $5 \%$ ZnDTP in the metalworking fluid presumably enabled a short running-in phase with a subsequently homogeneous progress of the friction coefficient. Accordingly, the wear in the synchronization during the shift tests was reduced by application of $5 \% \mathrm{ZnDTP}$. However, the further increase of the ZnDTP concentration in the metalworking fluid led to high fluctuations of the friction coefficient again and high wear distances in later operation. This indicates an unsuccessful generation of a tribologically effective phosphate glass layer. A possible explanation, therefore, could be the significantly lower grinding forces in the machining with 10\% ZnDTP. Due to the lower grinding forces, less energy was dissipated to heat what limited the formation of phosphate glass layers. Consequently, the high wear distance could not be avoided by these layers.

\section{Conclusions}

The presented results showed that metalworking fluid additives are able to influence the tribological properties of machined surfaces. For the grinding process of gear synchronizations, the concentration of the additives polysulfide (PS) and zincdialkyldithiophosphate (ZnDTP) has been varied between $0 \%, 5 \%$ and $10 \%$. Subsequently, the tribological properties in operation were tested over 7000 shifts on a special synchronization test facility. The development of the friction coefficient and the wear distance were the central parameters for characterization. 
The results showed that both additives influenced the tribological properties of the machined synchronizations. The addition of the PS caused a considerable reduction of friction coefficient fluctuations. Especially the concentration of 5\% PS led to a shorter running-in phase. Furthermore, the synchronizations that were machined with PS containing metalworking fluid showed lower wear distances in the shift tests, although these cones revealed a higher surface roughness which remained stable during the 7000 conducted shifts. This indicates the presence of chemical adsorption or reaction layers of PS on the machined surface which influenced the tribological properties of the synchronizations. The variation of the ZnDTP concentration in the applied metalworking fluid led to a modification of the tribological behavior of the synchronizations, too. The addition of $5 \% \mathrm{ZnDTP}$ reduced the running-in period, the friction coefficient fluctuations and the wear distance significantly. However, the further increase of the $\mathrm{ZnDTP}$ concentration to $10 \%$ led to higher friction coefficient fluctuations and higher wear again.

It can be concluded that the tribological properties of friction pairings can be modified by adjusting the metalworking fluid composition in the engaged metalworking process. In the case of gear synchronizations, a reduction of the friction coefficient fluctuations as well as the running-in period could be realized.

More precise conclusions could be possible by the direct measurement of chemical layers on the workpiece surfaces by appropriate high-resolution analysis methods. Thus, the investigated tribological behavior could be directly correlated to chemical modifications of the boundary layer.

Acknowledgments: The authors wish to thank the Deutsche Forschungsgemeinschaft (DFG) for funding the presented work within the project "Operational life time increasing boundary layer design by machining with specially added metalworking fluids at the example of lubricated metallic friction systems" (reference number AR 345/5-1). Furthermore, the authors thank the Institute of Machine Design and Tribology (IMKT) in Hannover for designing and conducting the tribological experiments and the Physics Institute (University of Münster) for the effective and cooperative collaboration within the research project.

Author Contributions: B. Seidel, A. Wagner and E. Brinksmeier designed the experiments and prepared the publication. B. Seidel performed the experiments and analyzed the data.

Conflicts of Interest: The authors declare no conflict of interest. The founding sponsors had no role in the design of the study; in the collection, analyses, or interpretation of data; in the writing of the manuscript, and in the decision to publish the results.

\section{References}

1. Clark, J.R.; Grant, M.B. The effect of surface finish on component performance. Int. J. Mach. Tools Manuf. 1992, 32, 57-66. [CrossRef]

2. Menezes, P.L.; Kishore; Kailas, S.V.; Lovell, M.R. Response of materials as a function of grinding angle on friction and transfer layer information. Int. J. Adv. Manuf. Technol. 2010, 49, 485-495. [CrossRef]

3. Goeke, S.; Biermann, D.; Stickel, D.; Stemmer, P.; Fischer, A.; Geenen, K.; Huth, S.; Theisen, W. Enhancing the Surface Integrity of Tribologically Stressed Contacting Surfaces by an Adjusted Surface Topography. Procedia CIRP 2014, 13, 214-218. [CrossRef]

4. Karpuschewski, B.; Welzel, F.; Risse, K.; Schorgel, M. Reduction of Friction in the Cylinder Running Surface of Internal Combustion Engines by the Finishing Process. Procedia CIRP 2016, 45, 87-90. [CrossRef]

5. Seidel, B.; Wagner, A.; Brinksmeier, E. Influence of dressing conditions in grinding process on tribological properties of gear synchronizations. HTM J. Heat Treat. Mater. 2017, in press.

6. Walter, A. Tribophysikalische und Tribochemische Vorgänge in der Kontaktzone bei der Zerspanung. Ph.D. Thesis, University of Bremen, Bremen, Germany, 2002.

7. Berlet, P.; Dienwiebel, M.; Scherge, M. The effect of sample finishing on the tribology of metal/metal lubricated contacts. Wear 2010, 268, 1518-1523. [CrossRef]

8. Kirchner, E. Leistungsübertragung in Fahrzeuggetrieben, Grundlagen der Auslegung, Entwicklung und Validierung von Fahrzeuggetrieben und anderen Komponenten; Springer: Berlin/Heidelberg, Germany, 2007.

9. Poll, G.; Spreckels, M. Influence of temperature distribution on the tribological performance of automotive synchronisers. Tribol. Ser. 2003, 41, 613-621. [CrossRef] 
10. Neudörfer, S. Thermomechanische Einflüsse auf Die Tribologie von Synchronisierungen. Ph.D. Thesis, University of Hannover, Hannover, Germany, 2008.

11. Lösche, T. Das tribologische Verhalten von Synchronisierungen unter Berücksichtigung des Beanspruchungskollektivs. Ph.D. Thesis, University of Hannover, Hannover, Germany, 1997.

12. Brinksmeier, E.; Meyer, D.; Huesmann-Cordes, A.G.; Herrmann, C. Metalworking fluids-Mechanisms and performance. CIRP Ann. Manuf. Technol. 2015, 64, 605-628. [CrossRef]

13. Martin, J.M.; Grossiord, C.; Le Mogne, T.; Bec, S.; Tonck, A. The two-layer structure of Zndtp tribofilms-Part I: AES, XPS and XANES analyses. Tribol. Int. 2001, 34, 523-530. [CrossRef]

14. Brüning, C. Massenspektrometrische Untersuchungen zum Einfluss der Temperatur auf die Bildung und Zusammensetzung tribologischer Schichten nasslaufender Synchronisationsreibkörper. Ph.D. Thesis, University of Münster, Münster, Germany, 2010.

15. Attar, H.; Ehtemam-Haghighi, S.; Kent, D.; Okulov, I.V.; Wendrock, H.; Bönisch, M.; Volegov, A.S.; Calin, M.; Eckert, J.; Dargusch, M.S. Nanoindentation and wear properties of Ti and Ti-TiB composite materials produced by selective laser melting. Mater. Sci. Eng. A 2017, 688, 20-26. [CrossRef]

16. Ehtemam-Haghighi, S.; Prashanth, K.G.; Attar, H.; Chaubey, A.K.; Cao, G.H.; Zhang, L.C. Evaluation of mechanical and wear properties of $\mathrm{Ti}-\mathrm{xNb}-7 \mathrm{Fe}$ alloys designed for biomedical applications. Mater. Des. 2016, 111, 592-599. [CrossRef]

(C) 2017 by the authors. Licensee MDPI, Basel, Switzerland. This article is an open access article distributed under the terms and conditions of the Creative Commons Attribution (CC BY) license (http:/ / creativecommons.org/licenses/by/4.0/). 